\title{
somA, a novel gene that encodes a major outer-membrane protein of Synechococcus sp. PCC 7942
}

\author{
Hiroyuki Umeda, Hirofumi Aiba and Takeshi Mizuno \\ Author for correspondence: Takeshi Mizuno. Tel: +8152789 4089. Fax: +81527894091.
}

Laboratory of Molecular Microbiology, School of Agriculture, Nagoya University, Chikusa-ku, Nagoya 464, Japan

\begin{abstract}
The outer membrane of a cyanobacterium (Synechococcus sp. strain PCC 7942) contains only a few major proteins. A gene encoding one of them, somA, was cloned and characterized. Based on the nucleotide sequence, SomA was predicted to comprise 531 amino acids with a calculated molecular mass of $57136 \mathrm{Da}$. The deduced amino acid sequence of SomA shares similarities with two bacterial cell-surface proteins, the S-layer protein of Thermus thermophilus and the flagellin of Campylobacter coli. The predicted amino acid sequence of SomA revealed also that it contains a signal peptide-like sequence at its $\mathbf{N}$ terminus. This signal peptide-like sequence was capable of mediating protein translocation across the cytoplasmic membrane into the outer membrane of Escherichia coli, provided that this sequence was fused to the $E$. coli outer-membrane protein, OmpF. The signal peptide-like sequence was cleaved upon the translocation of the SomA::OmpF protein. We suggest that SomA is synthesized as a precursor and that its $\mathbf{N}$-terminal 24 amino acid sequence is a cleavable signal peptide involved in protein targeting into the outer membrane. To our knowledge, this is the first example of cleavable signal peptides for proteins transported into the outer membrane of cyanobacteria.
\end{abstract}

Keywords: Synecbococcus, outer membrane, SomA protein, signal peptide, protein targeting

\section{INTRODUCTION}

Cyanobacteria can be defined as prokaryotes that have a photosynthetic apparatus similar in structure and function to that of higher plant chloroplasts. Like the majority of Gram-negative eubacteria, cyanobacteria possess an outer membrane as well as a cytoplasmic membrane. In this study, we cloned a gene encoding a major outermembrane protein (OMP) from one of the most commonly studied unicellular cyanobacteria, Synechococcus sp. strain PCC 7942.

We have studied the major OMPs, OmpF and OmpC, in Escherichia coli (Mizuno et al., 1983; Mizuno \& Mizushima, 1990). These pore-forming proteins (porins) are a paradigm for defining structure and function of the outer membrane in many Gram-negative bacteria. However,

Abbreviation: OMP, outer-membrane protein

The EMBLGenBank/DDBJ accession number of the nucleotide sequence reported in this paper is $D 64077$. little is known about the structure and function of the outer membrane of cyanobacteria, and as far as we know, there have been no reports on the cloning and characterization of genes encoding OMPs in cyanobacteria.

In cyanobacteria, exported proteins may have to be transported across the photosynthetic membranes (thylakoids) as well as the inner and outer membranes of the envelope. It is well established in E. coli that translocation of the majority of protein precursors across the membranes is mediated by the sec system (e.g. SecA and SecY) (Pugsley, 1993, and references therein). Synechococcus sp. strain PCC 7942 contains the SecA and SecY homologues (Nakai et al., 1992, 1994). Examples of signal peptides have been reported for cyanobacterial secretory precursors, but mostly for proteins transported into the thylakoid lumen (Kuwabara et al., 1987; Philbrick \& Zilinskas, 1988; Laudenbach et al., 1990, 1991; Briggs et al., 1990; Chitnis et al., 1991 ; Zhang et al., 1994 ; Shestakov et al., 1994). There have been no reports of a signal peptide for cyanobacterial OMPs. Thus, information on the characteristics of signal peptides specific for OMPs is 
needed to understand the molecular mechanism underlying differential protein targeting in cyanobacteria.

\section{METHODS}

Bacterial strain and growth conditions. Synechococcus sp. strain PCC 7942 was grown at $30^{\circ} \mathrm{C}$ in BG11 medium supplemented with $20 \mathrm{mM} \mathrm{N}$-tris(hydroxymethyl)methyl-2-amino-ethanesulphonic acid (TES)-KOH (pH 8.0) (Rippka et al., 1979). For liquid cultivation, the culture was continuously aerated. Continuous illumination was provided by fluorescent lamps. When required, kanamycin was added at a concentration of $30 \mu \mathrm{g} \mathrm{ml}^{-1}$. E. coli $\mathrm{K} 12 \mathrm{MH} 1160\left[\operatorname{rec} A\left(\mathrm{~F}^{-} \Delta\right.\right.$ lacU169 araD139 rpsL relA thi $A$ fibB syr $A$ ompR $101 \operatorname{rec} A$ )] was used for expression of the Som A : OmpF fusion protein.

Plasmid construction. Plasmid pUME7 was constructed as follows. A 355 bp EcoRI fragment encoding a portion of the som $A$ gene was isolated from recombinant $\lambda$ gt11 phage (see below) and cloned into the EcoRI site of pUC118 (Vieira \& Messing, 1987). A $5.3 \mathrm{~kb}$ Sall-SphI fragment encompassing the som $A$ gene was isolated from the chromosomal DNA of Synecbococcus sp. PCC 7942 and ligated into the SalI-SphI site of pKT01 (a derivative of pSC101, unpublished) to yield pHAI182. Plasmid pSomA : OmpF was constructed as follows (see Fig. 6). Firstly, a $616 \mathrm{bp} X b a \mathrm{I}-E c o$ RI fragment, encoding the putative signal peptide of the $\operatorname{som} A$ gene, was isolated from pHAI182 and ligated into the XbaI-EcoRI site of pIN-IIIA3 (Masui et al., 1984) to yield pUME14. A $1.6 \mathrm{~kb}$ PstI fragment, encoding the ompF gene, was isolated from pMAN007 (Matsuyama et al., 1984) and ligated into the $P_{s t I}$ site of PUC119 (Vieira \& Messing, 1987). From the resultant plasmid, a $1.6 \mathrm{~kb}$ HindIII and BamHI fragment was isolated and ligated into the HindIIIBamHI site of pUME14 to yield pSomA::OmpF.

Construction of deletion/insertion mutant. The EcoRI-EcoRI region of plasmid pHAI182, which corresponds to an internal region of the $\operatorname{som} A$ gene, was replaced by a $1.4 \mathrm{~kb}$ EcoRI fragment of pSI029 containing the neo (neomycin phosphotransferase) gene (Suzuki et al., 1987) to yield pUME13. Wildtype Synechococcus sp. PCC 7942 was directly transformed by this plasmid, which cannot propagate in the cyanobacterium, and kanamycin-resistant colonies were selected as candidates carrying the $\operatorname{som} A:$ neo mutation on the chromosome.

DNA techniques. For nucleotide sequence analysis, a set of restriction fragments derived from pHAI182 encompassing the $\operatorname{som} A$ gene was subcloned into pLC119 (Vieira \& Messing, 1987). The generation of successively shortened DNA fragments for nucleotide sequencing was performed using a kilosequence deletion kit (Takara Shuzo). The sequence analyses were performed with a DNA sequencer (Applied Biosystems Model 373A) using a PRISM Ready Reaction DyeDeoxy Terminator Cycle Sequencing Kit (Applied Biosystems). For hybridization experiments, the DIG DNA Labelling and Detection Kit (non-radioactive; Boehringer Mannheim) was used.

Isolation of SomA. Synechococcus sp. PCC 7942 was grown in 41 BG11 medium for $3 \mathrm{~d}$. From $5 \mathrm{~g}$ (wet wt) of cells, the envelope fraction was prepared as described by Murata \& Omata (1988). This fraction was treated with $1 \%(\mathrm{w} / \mathrm{v})$ sodium $N$-lauroyl sarcosinate in buffer containing $10 \mathrm{mM}$ TES-NaOH $(\mathrm{pH} 7 \cdot 0)$, $1 \mathrm{mM}$ EDTA and $10 \mathrm{mM} \mathrm{NaCl}$ for $30 \mathrm{~min}$ at $20^{\circ} \mathrm{C}$. The insoluble fraction was collected by centrifugation at $100000 \mathrm{~g}$ for $1 \mathrm{~h}$. This fraction was subjected to SDS-PAGE, and Som proteins were purified from the gel by electroelution. This fraction was used as an antigen to raise a polyclonal anti-Som antiserum in mice.

Screening of a $\lambda$ gt11 expression library. An expression library, prepared from Synechococcus sp. PCC 7942 genomic DNA in $\lambda \mathrm{gt11}$, was screened using an anti-Som antiserum as a probe. The method was essentially the same as that described by Snyder \& Davis (1985). Phosphatase-labelled goat antiserum raised against mouse immunoglobulins was used as an indicator.

Preparation of $E$. coli cell envelopes and analysis by ureaSDSPAGE. The OMPs of E. coli were prepared by extraction of the cell envelope with sodium $N$-lauroyl sarcosinate as described by Filip et al. (1973). The OMPs were characterized by ureaSDS-PAGE as described by Mizuno \& Mizushima (1987).

Amino acid sequencing. The Som $\mathrm{A}: \mathrm{OmpF}$ fusion protein, expressed in the outer membrane of E. coli, was separated by urea-SDS-PAGE (see Fig. 7) and transferred onto a PVDF membrane. Amino acid sequencing was performed with an automated amino acid sequencer (Applied Biosystems Model 476A).

\section{RESULTS}

\section{Isolation of OMPs}

A total cell-membrane fraction, containing the inner, outer and thylakoid membranes, was prepared from Synecbococcus sp. PCC 7942 (Fig. 1, lane 1). An outermembrane-enriched fraction was then isolated by means of sucrose density-gradient centrifugation (Murata \& Omata, 1988). This fraction was treated with a mild

(a)

(b)

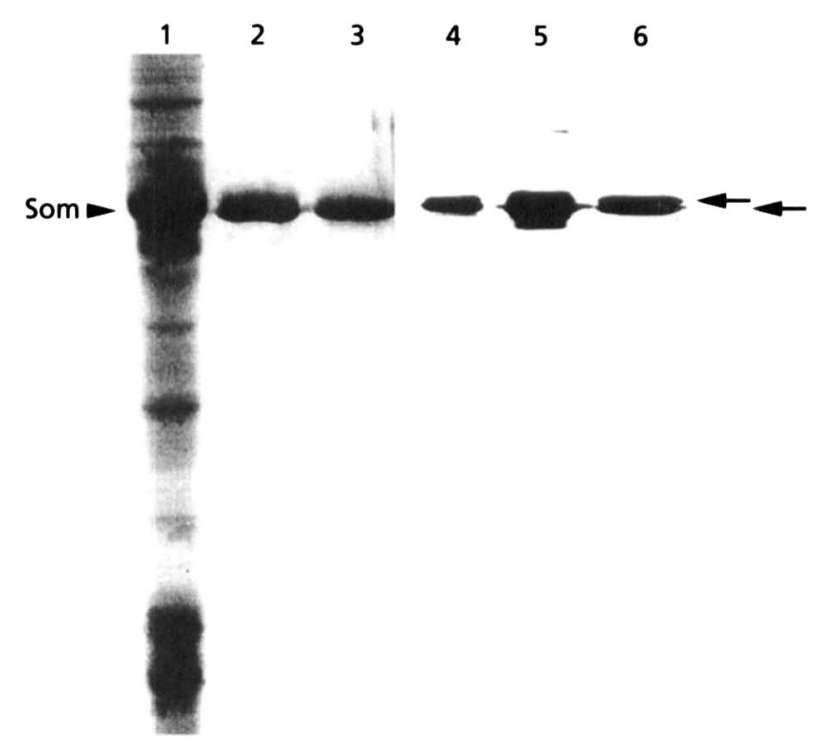

Fig. 1. SDS-PAGE analysed by Coomassie Brilliant Blue staining (a) or immunoblotting with the anti-Som antiserum (b). Lanes: 1 and 4 , total cell envelope proteins, $80 \mu \mathrm{g}$ protein; 2 and 5 , purified OMPs, $8 \mu \mathrm{g} ; 3$ and 6 , purified Som proteins, $3 \mu \mathrm{g}$. Note that the purified Som proteins consist of at least two major polypeptides, as indicated by the arrows on the right (see lane 6). 


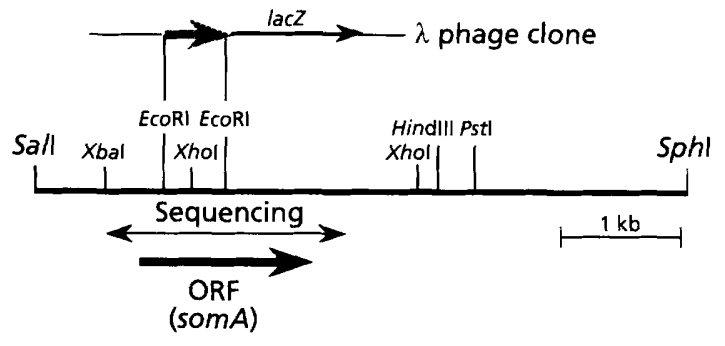

Fig. 2. Schematic representation of the structure of the region containing the Synechococcus sp. PCC 7942 somA gene. The structure of a $\lambda$ phage clone is shown at the top in which the Synechococcus sp. PCC 7942 EcoRI-EcoRI DNA segment was inserted in front of the lac $Z$ gene. The sequenced region is indicated by the bi-directional arrow, in which an ORF (the putative somA gene) was found, as indicated by the bold arrow.

detergent (sodium $N$-lauroyl sarcosinate) and the insoluble protein fraction, presumably containing OMPs, was recovered by centrifugation. Its protein composition was analysed by SDS-PAGE, followed by Coomassie Brilliant Blue staining (Fig. 1a). A major protein band was detected on the gel (lane 2). This band was considered to correspond to major OMP(s) and apparently consisted of only a few polypeptides (tentatively referred to as 'Som', Synechococcus outer-membrane proteins). Som proteins were recovered from the polyacrylamide gel by electroelution (lane 3). This Som-enriched fraction was used for preparation of a polyclonal anti-Som antiserum in mice. The same set of protein fractions as those characterized in Fig. 1a were also subjected to an immunoblotting analysis with the resultant polyclonal anti-Som antiserum, (Fig. 1b). The results showed that the anti-Som antiserum recognizes the Som proteins in a highly specific manner (lane 4), and also that the isolated Som fraction appears to contain at least two major polypeptides (lane 6).

\section{Cloning a gene}

A $\lambda$ gt11 expression library in E. coli, prepared from Synechococcus sp. PCC 7942 genomic DNA, was screened by means of immunoblotting with the anti-Som antiserum. From among $5 \times 10^{5}$ phages, nine positive clones were isolated. Restriction mapping and Southern hybridization analyses of these phage DNAs indicated that they each carried an overlapping DNA segment, but of different length. One of the clones was found to carry a $350 \mathrm{bp}$ EcoRI-EcoRI fragment of Synechococcus sp. PCC 7942 DNA, which was shared among all of the other clones (Fig. 2). The nucleotide sequence of this EcoRI fragment revealed a potential ORF fused in-frame to the coding sequence of $\beta$-galactosidase derived from the expression vector (Fig. 2). This implied that the cloned DNA encompasses only a portion of the putative som gene. Therefore, total genomic DNA from Synechococcus sp. PCC 7942, digested with various restriction enzymes, was extensively analysed by Southern hybridization with the EcoRI fragment as a probe. A $5.3 \mathrm{~kb} S a l \mathrm{~L}-S p h \mathrm{I}$ fragment of Synechococcus sp. PCC 7942 DNA, which hybridized with the EcoRI probe, was subsequently cloned to yield plasmid pHAI182 (see Methods). This fragment was confirmed to contain the EcoRI-EcoRI region in question (Fig. 2). It should be noted here that we identified only this type of clone during this screening. Although the anti-Som antiserum appeared to cross-react with two distinct major polypeptides, we did not detect another DNA sequence (see Fig. 1b). We assumed that the cloned SalI-SphI region may contain the coding sequence for one of the Synechococcus sp. PCC 7942 major OMPs.

\section{Nucleotide sequence of the somA gene}

The determined nucleotide sequence of the approximately $2 \mathrm{~kb}$ region surrounding the EcoRI sites revealed an ORF encoding 531 amino acids, which is preceded by a good prokaryotic ribosome binding site (GAGG) (Fig. 3). A potential transcription start site was determined by primer extension analysis (underlined $G$ residue at position 195 in Fig. 3). A pair of prokaryotic canonical promoter sequences ( -35 and -10 regions) were tentatively assigned as TAGTTT and TACCTT. However, the Nterminal amino acid sequence of the purified Som protein could not be determined, probably because of a modification. Thus, both the identity of this ORF and its initial methionine could not be verified.

The putative som $A$ gene was disrupted in the chromosome of Synechococcus sp. PCC 7942 by gene replacement using an insertionally inactivated $\operatorname{som} A:$ : neo gene (Fig. $4 \mathrm{a}$, see Methods). Homologous double recombination in the chromosome was confirmed by Southern hybridization with the Sall-digested DNA (Fig. 4b). The cell envelope fraction was isolated from the som $A::$ neo deletion/ insertion mutant, and its protein composition was compared with that of the parental strain by SDS-PAGE (Fig. $4 c)$. These results showed that the mutant strain lacks a major protein in the envelope (SomA), although it still contains another one (named SomB) encoded by a separate gene.

\section{Features of the predicted amino acid sequence for SomA}

As described above, the translation start site could not be experimentally identified for Som A. However, the amino acid sequence of SomA was predicted to comprise 531 residues with a calculated molecular mass of $57136 \mathrm{Da}$ (Fig. 3). This value is slightly larger than that estimated for the isolated SomA protein on SDS-PAGE (i.e. $55 \mathrm{kDa}$ ). In this respect, it should be pointed out that the predicted amino acid sequence contains a signal peptidelike sequence at its $\mathrm{N}$ terminus (see Fig. 3, underlined sequence). There is a hydrophobic core sequence preceded by positively charged amino acids (Lys and Arg) followed by amino acids with no or small side chains (Gly and Ala). All these characteristics are consistent with those proposed generally for bacterial signal peptides (von Heijne, 1994). If this is the case, then the difference between the estimated and calculated molecular masses may be reason- 
$\underline{X b a} I$

TCTAGAGCTACGGCACTAGTTAGTTAATCCTTGGGAGAGGGTGGGGTCCGCAAGATCTCACCCTCTCTGTTTTGAGGGAAAGCTGGGTT TGGGTGACCTCCTTGAGAGAAGTGITGCAAGTITTGCAAAACGITCATGCAGGATGTGTTCCAGAAGACTAGTTITITGACAAGGGATTT $-35$ GTTACCTTACCTTCGTGAGAAGTGATCTACCCATTTCTCCCTACATGGTGTGAGGTTATCAATGAACGCCTITTCTCGGCGCTGCTTCT $-10 \quad$ SD $\quad$ M K R R L F S A L L L AGCCCCGGCAATTGCTGGTGTGGCTGCGGGCGCAGCAAATGCTAACGGTTTAAGCACCGAACAGCTCCAAAAAATTGACGCTGTAACTCC

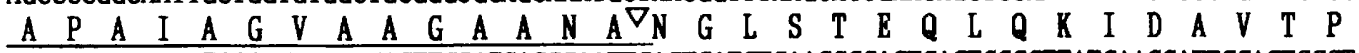
CAACGGCATCACCTCCGGTCAGATCACTTCGATCACCGAATTGAGTGATGTCAAGCCGACTGACTGGGCTTATCAAGCATTGCAGTCGCT N AGTTGAGCGITATGGCTGCATCGTCGGCTACCCTGATCGGACTTACCGTGGTAGCCGCCCCCTCTCTCGITATGAGTTTGCAGCAGGCTT

$\begin{array}{llllllllllllllllllllllllllllllll}V & E & R & Y & G & C & I & V & G & Y & P & D & R & T & Y & R & G & S & R & P & L & S & R & Y & B & F & A & A & G & L & 100\end{array}$ BCOR I GAACGCTTGCTTGGACAAAGTCATTGAATTT GCAGCGTCGAAAGAGGATCTCGACACCCTCAAGCGACTGACTGAAGAATTCCAAGCTGA 630 $\begin{array}{lllllllllllllllllllllllllllllll}\text { N } & \text { A } & C & \text { L } & \text { D } & \text { K } & \text { V } & \text { I } & \text { E } & \text { F } & \text { A } & \text { A } & \text { S } & \text { K } & \text { B } & \text { D } & \text { L } & \text { D } & \text { T } & \text { L } & \text { K } & \text { R } & \text { L } & \text { T } & \text { B } & \text { B } & \text { F } & \text { Q } & \text { A } & \text { B } & 130\end{array}$ GCTGGCGACCCTGCGTGGTCGTGTTGATAGT CTCGAGGCTCGTGTTAAAGAGCTCGAAGCTACCCGITTCTCCACCACGACTAAGCTACA

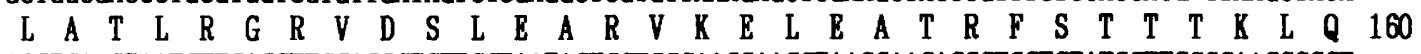
AGGTGAAGTAATCTTCAGCTTGGACGCTGTT GCTAATACTGCTGGCAACGAACGTAACCAAGACGGTGCTGTATCGITCGGCAACCGCGT 810 $\begin{array}{lllllllllllllllllllllllllllllll}\text { G } & \text { E } & \text { V } & \text { I } & \text { F } & \text { S } & \text { L } & \text { D } & \text { A } & \text { V } & \text { A } & \text { N } & \text { T } & \text { A } & G & N & \text { R } & R & \text { N } & \text { Q } & \text { D } & G & \text { A } & \text { V } & \text { S } & \text { F } & G & N & R & V & 190\end{array}$ CAGCTTGAACCTCAACACGAGCTTCACTGGCAAAGACTTGCTATTGACCCGTCTGCGCGCTCGTAACATTGAGACGATTCAGCAGCGCTT

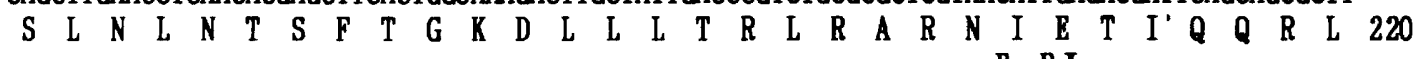
RCOR I

GTCGCCTGGCTTTAATCCCTCGGECTCGCGGCTCGACTACGACGGTACCGGITCGCCTGGTGTCCCGAATTCGGCTAATACCTTTITCCT 990 $\begin{array}{lllllllllllllllllllllllllllllll}S & P & G & F & N & P & S & G & S & R & \text { L } & D & Y & D & G & T & G & S & P & G & V & P & N & S & A & N & T & \text { P } & \text { P } & \text { L } & 250\end{array}$ TGACAAATTGCTGTACCGCTTCCCCGTCGGT GATGTCTCCTTCACTGITGGTACCGCGGGCGTTCAACCTCAAGACTACGCCCTGAGCGA 1080

$\begin{array}{lllllllllllllllllllllllllllllll}D & K & \text { L } & \text { L } & \text { Y } & R & \text { F } & \text { P } & \text { V } & G & \text { D } & \text { V } & \text { S } & \text { F } & \text { T } & \text { V } & G & \text { T } & \text { A } & G & \text { V } & \text { Q } & \text { P } & Q & \text { D } & \text { Y } & G & \text { L } & S & D & 280\end{array}$ CGCTACCTTCTTCAGTGGCCCTGCGAACACGAAAGCCTTCAAGTATGTCGGTGCAGGIGITTACGCTGATACTCGTGATGCTGATACCGC 1170

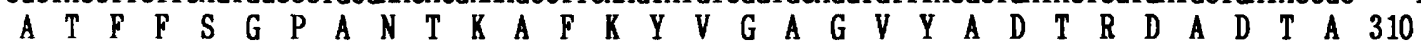
TGGTGTTGGCTTCAACTGGAAGGCTAGTAAGAATTTCAGCTTCCAGCCTGGCTACATCAACCGCAACTCTGCTGATGTCTCGACTGTCAA 1260 $\begin{array}{lllllllllllllllllllllllllllllll}G & V & G & F & N & W & K & A & S & K & N & F & S & F & Q & A & G & Y & I & N & R & N & S & A & D & V & S & T & V & N & 340\end{array}$ CAGTGGTGGTGTCTTTGGCTTCACCCCGACAGGGACTGGTACTAACTCTTGGGATGTGAATGCTCAAGTCAAGTACCAAACTGATAACAA 1350 $\begin{array}{lllllllllllllllllllllllllllllll}\text { S } & G & G & V & F & G & F & T & P & T & G & T & G & T & N & S & \text { W } & D & V & N & A & Q & V & K & Y & Q & T & D & N & N & 370\end{array}$ CAAGTTCCGAGTTGCTCTGGCCTACGCTCTGCCAAATGGTCGCTACGCCACTGACTTCGGTACCACCAACGCCTTCCAGCCTTTTGGTGC 1440

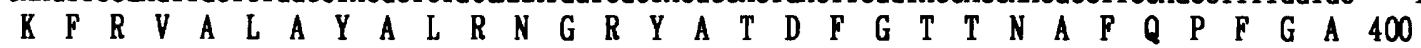
TACCAACTACAACAGCAACAACCTTGCTCTCTCCTTGGGTTGGGCAATTCTGATGCTGTGACCTTGTCAGCCGGCTACGGCATTGGCTT $\begin{array}{lllllllllllllllllllllllllllllll}T & N & Y & N & S & N & N & L & A & L & S & \text { L } & G & W & A & I & S & D & A & V & T & \text { L } & \text { S } & \text { A } & G & \text { Y } & \text { G } & \text { I } & \text { G } & \text { F } & 430\end{array}$ TGTCAATGAGCAAGGTACGAACCAAAACGCGACTGTTCAGAACTACGCAATTGGCTTGACCTTCCCTAACCTGITTGCTGATGGCAACGA 1620 $\begin{array}{lllllllllllllllllllllllllllllll}V & N & E & Q & G & T & N & Q & N & A & T & V & Q & N & Y & A & I & G & \text { L } & T & F & P & N & \text { L } & \text { F } & \text { A } & \text { D } & G & N & \text { B } & 460\end{array}$ GTTTGGTGTTCAGCAGGCCAACAACCTTGGGTCAGCAGCGCTTCTAACCGITCGTCTGAAGACACTGGTTCCTITGGTGITGAAACCTA 1710 $\begin{array}{lllllllllllllllllllllllllllllllll}F & G & V & A & A & G & Q & Q & P & W & V & S & S & A & S & N & R & S & S & B & D & T & G & S & F & G & V & B & T & Y & 490\end{array}$ CTACAAATTCCAAGTGACGGACAATATCTCCATCACTCCTGGTATTTACGTGTTCAACAACACCAATGGCCAGCAAAACGGTGGAACGAC

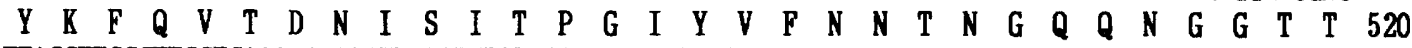
TTACGITCCCTTCCTGAAAACAGTCTTCCGTTICTAGGAATCAACTGTTTAGITAGGGATGGGCGATCGCATCCTAACCAACTCTTTCCT $\begin{array}{lllllllllllll}\text { Y } & V & P & \text { F } & \text { L } & K & \text { T } & \text { V } & F & R & F & *\end{array}$ 531

Fig. 3. The nucleotide and deduced amino acid sequences of the somA gene. The transcription start site of somA, determined by primer extension analysis, is indicated by the underlined $G$ at position 195. A signal peptide-like sequence is underlined and a possible cleavage site is indicated by $\nabla$.

ably explained by assuming that the som $A$ gene specifies a precursor.

A computer-aided search (using the PIR and Swiss-Prot databases, provided by the DDBJ e-mail server) revealed that SomA shares certain similarities with two other known bacterial proteins, although each similar region is located at different and limited portions of SomA (Fig. 5). A 90 amino acid sequence of SomA (positions 50-140) appears to be significantly similar to a portion of the Slayer protein of Thermus thermophilus (Fig. 5b) (Faraldo et al., 1992). This $\mathrm{N}$-terminal region of SomA is followed by a 200 amino acid region (positions 140-340), which resembles a portion of the flagellin (FlaA) of Campylobacter coli (Fig. 5c) (Guerry et al., 1991). It should also be noted that a more extensive similarity was found between SomA and a hypothetical protein predicted previously in another cyanobacterium, Synechocystis sp. strain PCC 6803 (data 
(a)

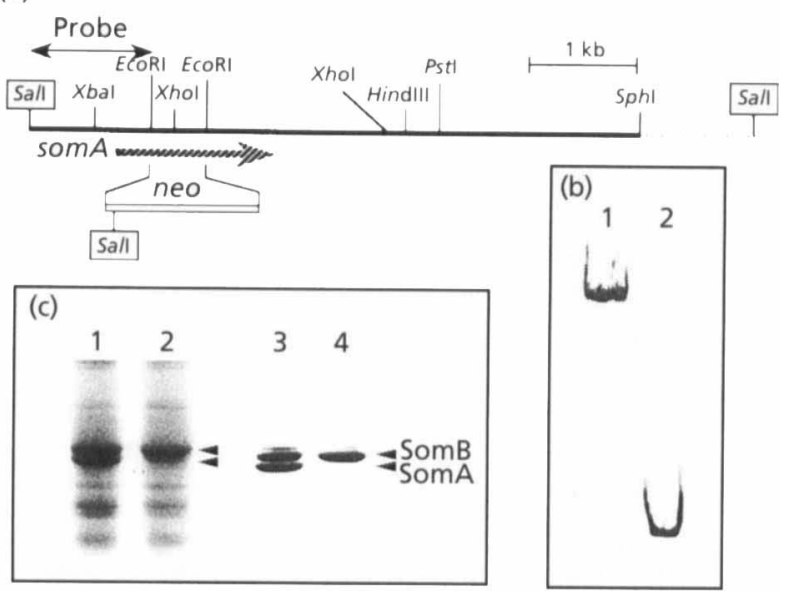

Fig. 4. (a) Restriction map of the Synechococcus sp. PCC 7942 genomic DNA encompassing the somA gene, and isolation of an insertional inactivation mutant. To construct a somA::neo deletion/insertion mutant (designated as $\triangle$ somA), the neo (kanamycin resistance) gene was inserted between the EcoRI sites as described in Methods. (b) Southern hybridization analysis of the chromosomal DNA from the somA deletion (lane 2) and wild-type cells (lane 1) was carried out with the Sall-EcoRI segment shown in (a) as the probe. (c) SDS-PAGE of the cell envelope proteins analysed by Coomassie Brilliant Blue staining (lanes 1 and 2) or immunoblotting (lanes 3 and 4), prepared from the somA deletion (lanes 2 and 4) and wild-type cells (lanes 1 and 3 ).

not shown) (Zhang et al., 1989). However, nothing is known about this hypothetical protein.

\section{The signal peptide-like sequence of SomA mediates protein translocation into the outer membrane of $E$. coli}

As mentioned above, it was not possible to demonstrate that SomA has a cleavable signal peptide. Thus we addressed this issue using a model prokaryotic species, $E$. coli. E. coli $\mathrm{K} 12$ possesses the well-characterized $\mathrm{OmpF}$ which is synthesized as a precursor with a typical cleavable signal peptide (Fig. 6a) (Mizuno et al., 1983). We constructed a $\operatorname{som} A:: o m p F$ fusion gene which could specify a SomA : OmpF fusion protein, in which an $\mathrm{N}$ terminal portion of SomA was fused to the entire region of the mature OmpF protein (Fig. 6a). This particular fusion gene was constructed on an $E$. coli expression vector (plasmid pSomA::OmpF, see Methods). This plasmid was introduced into an $E$. coli mutant lacking OmpF and its expression was induced under the lac-lpp promoter of the plasmid. OMPs were purified from the $E$. coli cells and analysed by SDS-PAGE (Fig. 6b). A large amount of SomA : : OmpF fusion protein was synthesized and translocated into the E. coli outer membrane (lanes + in Fig. 6b; note that in the immunoblotting analysis the smaller band appears to be a degradation product of Som A::OmpF). It is known that OmpF in the E. coli (a)

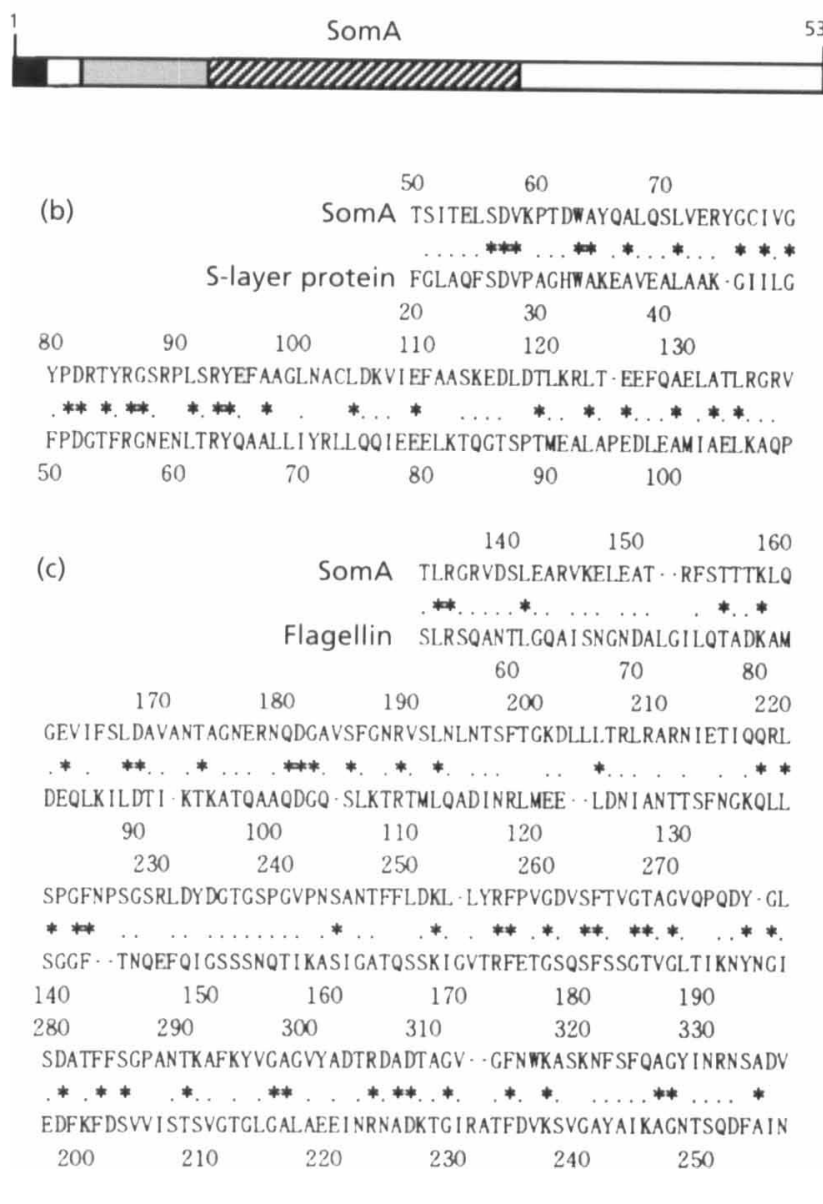

Fig. 5. Characteristic features of the primary structure of SomA. (a) A schematic representation of the structure of SomA. The signal peptide-like sequence $(\boldsymbol{D})$ is followed by a region similar to the S-layer protein of Thermus aquaticus (for the sequence comparison, see b) (圆). This S-layer-protein-like region is followed by a region similar to the flagellin (FlaA) of $C$. coli (for sequence comparison, see c) ( 6 ). In (b) and (c), the respective sequences were aligned using the FASTA program. Identical and similar amino acids are highlighted by asterisks and dots, respectively.

outer membrane functions as an essential receptor for phage Tu-Ia (Datta \& Henning, 1977). E. coli cells producing the Som A::OmpF fusion protein supported the propagation of $\mathrm{Tu}-\mathrm{Ia}$, while the $\mathrm{OmpF}^{-}$strain did not (Fig. 6c). This result indicated that the SomA::OmpF fusion protein can be properly incorporated into the outer membrane, thereby functioning as the receptor for 'Tu-Ia. The SomA::OmpF fusion protein was purified and subjected to $\mathrm{N}$-terminal amino acid sequencing. The deduced sequence of Asn-Gly-Leu-Ser-Thr-Glu corresponds exactly to the amino acid sequence found in the near $\mathrm{N}$ terminus of Som $\mathrm{A}$, extending from positions 25-30 (Fig. 6d). Collectively, these results imply that the $\mathrm{N}$-terminal 24 amino acid sequence of SomA can function as a cleavable signal peptide in E. coli. We believe that this is most likely the case also in Synechococcus sp. PCC 7942. 
(a)

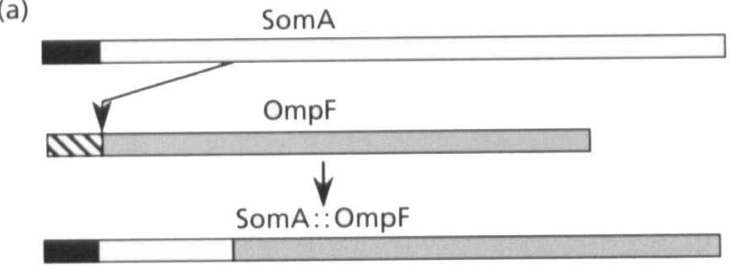

(b)

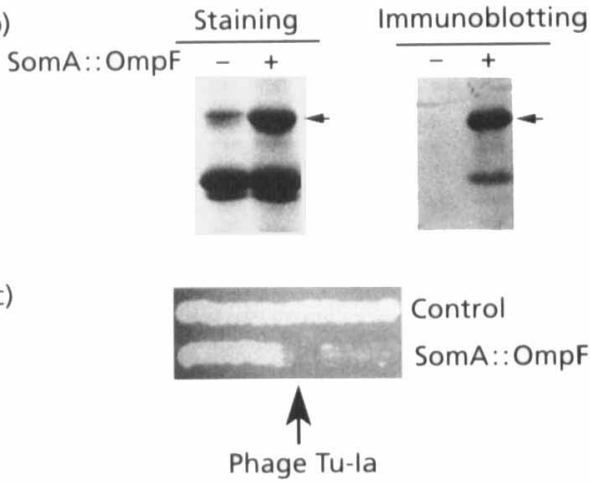

(d)

Fig. 6. Characterization of a somA::ompF translational fusion gene encoding a SomA::OmpF fusion protein in $E$. coli. (a) Structure of the SomA::OmpF protein. The approximate location of the sites at which the SomA and OmpF proteins were fused together are shown by the arrow. (b) SDS-PAGE analysed by Coomassie Brilliant Blue staining or immunoblotting with a monoclonal anti-OmpF antiserum. $E$. coli OMPs were purified from the cells producing the SomA::OmpF protein and then analysed by SDS-PAGE (lanes + ) by comparison with the sample from the control cells (OmpF-' lanes -). (c) A cross-streak test with $E$. coli phage Tu-la. A lysate of Tu-la was pre-streaked on plates, then either the $E$. coli cells producing the SomA::OmpF protein or the control cells $\left(\mathrm{OmpF}^{-}\right)$were cross-streaked against it. The plates were incubated at $37^{\circ} \mathrm{C}$ overnight, and then photographed. (d) The putative signal sequence of SomA. The cleavage site was determined for the isolated SomA::OmpF protein (see $b$; the band corresponding to SomA::OmpF was isolated from the gel by electroelution. The sample was then directly analysed by an automated amino acid sequencer. Based on this result, the cleavage site was determined, as indicated by the arrowhead.

\section{DISCUSSION}

This study is the first report of the cloning and sequencing of a gene $(\operatorname{som} A)$ encoding a major OMP of the unicellular cyanobacterium Synechococcus sp. PCC 7942. SomA is one of the most abundant proteins of the total envelope proteins of Synechococcus sp. PCC 7942 (see Fig. 1, lane 1). The physiological function of Som $A$ is not known at present, since we have not been able to detect any noticeable phenotype for a $\operatorname{som} A:$ neo deletion/insertion mutant under the growth conditions tested (see Fig. 4). E. coli $\mathrm{K} 12$ has three major OMPs, OmpA, OmpC and $\mathrm{OmpF}$, each numbering approximately $10^{5}$ to $10^{6}$ molecules per cell. Both OmpC and OmpF play an important physiological role by forming voltage-gated passive diffusion pores (porin) which allow small molecular weight hydrophilic materials to cross the outer membrane

(Nikaido, 1979). With regard to its primary sequence, SomA is not similar to the OmpC and OmpF proteins. Voltage-gated porins are also known to exist in plant chloroplasts and their predicted sequences have recently been reported for non-green plastids from pea and maize (Fischer et al., 1994), but the reported amino acid sequences are not similar to that of SomA. Recently, a pore-forming protein was purified from the outer membrane of Synechococcus sp. PCC 6301 (Hansel et al., 1994). The apparent molecular mass of this protein was estimated by SDS-PAGE to be about $52000 \mathrm{Da}$, similar to that of SomA. It is not known at present whether or not these two proteins from different Synechococcus species are homologous. In any case, it may be worth mentioning that Synechococcus sp. PCC 7942 has another major OMP (SomB) which is encoded by a gene distinct from $\operatorname{som} A$ (see Fig. 4).

While the physiological function of Som A is not known at present, it shares certain similarities with two proteins, the cell-surface S-layer protein of $T$. thermophilus and the flagellin of $C$. coli (see Fig. 5). In particular, the polymeric S-layer protein appears to play a structural role. By this analogy, SomA may play a structural role by forming a protein layer on the cell surface.

Some of the thylakoid proteins in cyanobacteria must be transported completely across the thylakoid membrane into the thylakoid lumen, whereas cell envelope proteins must be transported across the cytoplasmic membrane into either the periplasmic space or the outer membrane. A crucial question is the mechanism responsible for the ability of cyanobacteria to discriminate between these two pathways for proper protein targeting. Are there two distinct types of translocation machinery in cyanobacteria, or are there two types of signal peptides for secretory precursors, one specific for the thylakoid lumen proteins and the other for the cell envelope proteins? Although several recent studies have addressed these questions, a clear answer has not emerged (Nakai et al., 1992, 1994; Barbrook et al., 1993; Mackle \& Zilinskas, 1994; Chaddock et al., 1995; Varley et al., 1995; Packer et al., 1995). The results implied that the cytoplasmic and thylakoid membranes share a common protein translocation machinery, which includes Sec proteins (e.g. SecA and SecY) as well as signal peptide peptidases (Kuwabara et al., 1987; Philbrick \& Zilinskas, 1988; Laudenbach et al., 1990; Briggs et al., 1990; Chitnis et al., 1991; Zhang et al., 1994; Shestakov et al., 1994). In this study, we compiled a list of putative signal peptide sequences for comparison to SomA; these include the periplasmic protein ( $\mathrm{RhdA}$, a rhodanese-like protein of Synecbococcus) (Laudenbach et al., 1991), as well as a number of thylakoid lumen proteins (Fig. 7). The listed signal peptides all resemble each other with respect to their structural features. Specifically, they contain a positively charged $\mathrm{N}$-terminal domain, a hydrophobic core sequence and a conserved signal peptide cleavage site. These are well-known characteristics for eubacterial signal peptides (von Heijne, 1994). This observation explains the basis that the SomA signal peptide is capable of functioning in the translocation of OmpF in E. coli (see Fig. 6). It should be emphasized that 
SomA (Synechococcus) (OM): RhdA (Synechococcus) (PS):

$33 \mathrm{kDa}$ (Synechococcus) (TL): $33 \mathrm{kDa}$ (Synechocystis) (TL): PetE (Synechocystis) (TL) PetJ (Synechocystis) (TL): PsaF (Synechocystis) (TL): CtpA (Synechocystis) (TL): CytA (Synechococcus) (TL):

MKR LFSALlLaPaiagVaA GAANA ngl MSVRSLRWPROK AFLAVISLVVAVLLAVPGRL TPATA asq

MRYR AFLAAFLAVCLGVLTACSS GPTAA dIg MKR ILGTAIAALVVLLAFI APAQA ad! MRFR PSIVALLSVCFGLLTFLYYS GSAFA vdk MSKK FLTILAGLLLVVSSFFLSVS PAAAA nat MFKLFNQASR IFFGIALPCLIFLGGIFSLG NTALA adl MKHKK ALLLAFTLWFNFA PSASA ddf MGKRTRR FWALAFSLLMGALIYLGNT PSALA $\mathrm{fte}$

Fig. 7. Comparison of the primary structures of cyanobacterial signal peptides. The SomA OMP (OM) was characterized in this study. The RhdA protein has been reported to be transported into the periplasmic space (PS). All others are known to be transported into the thylakoid lumen (TL). In each sequence, for clarity, a positively charged N-terminal domain (left), a hydrophobic core sequence (centre) and a conserved signal peptide cleavage site (right, arrowhead) are presented separately. The lower case letters for each sequence indicate the presumed $\mathrm{N}$-terminal sequence of the corresponding mature form. These sequences (from top to bottom) were from those reported by Laudenbach et al. $(1991,1990)$, Kuwabara et al. (1987), Philbrick \& Zilinskas (1988), Briggs et al. (1990), Zhang et al. (1994), Chitnis et al. (1991) and Shestakov et al. (1994).

the SomA signal peptide appears indistinguishable from, for instance, that of the thylakoid lumen protein, Cyt $A$ (cytochrome c-553) (Fig. 7). These comparisons imply that protein targeting in cyanobacteria may not be achieved by radical differences in signal peptide structure.

\section{ACKNOWLEDGEMENTS}

We thank Drs N. Murata and T. Omata for helpful discussions. This study was supported by a Grant-in-Aid for Scientific Research on a priority area (No. 04273013) from the Ministry of Education, Science and Culture of Japan.

\section{REFERENCES}

Barbrook, A. C., Packer, J. C. \& Howe, C. J. (1993). Components of the protein translocation machinery in the thermophilic cyanobacterium Phormidium laminosum. Biochem Biophys Res Commun 197, 874-877.

Briggs, L. M., Pecoraro, V. L. \& McIntosh, L. (1990). Copperinduced expression, cloning, and regulatory studies of the plastocyanin gene from the cyanobacterium Synechocystis sp. PCC6803. Plant Mol Biol 15, 633-642.

Chaddock, A. M., Mant, A., Karnauchov, I., Brink, S., Herrman, R. G., Klösgen, R. B. \& Robinson, C. (1995). A new type of signal peptide: central role of a twin-arginine motif in transfer signals for the $\triangle \mathrm{pH}$-dependent thylakoidal translocase. EMBO J 14, 27152722.

Chitnis, P. R., Reilly, P. A., Miede, M. \& Nelson, N. (1989). Structure and targeted mutagenesis of the gene encoding $8-\mathrm{kDa}$ subunit of photosystem I from the cyanobacterium Synechocystis sp. PCC 6803. $J$ Biol Chem 264, 18374-18380.

Datta, D. B., Arden, B. \& Henning, U. (1977). Major proteins of the Escherichia coli outer cell envelope membrane as bacteriophage receptors. J Bacteriol 131, 821-829.

Faraldo, M. M., Pedro, M. A. \& Berenguer, J. (1992). Sequence of the S-layer gene of Thermus thermophilus HB8 and functionality of its promoter in Escherichia coli. J Bacteriol 174, 7458-7462.
Filip, C., Fletcher, G., Wulff, J. L. \& Earhart, C. F. (1973). Solubilization of the cytoplasmic membrane of Escherichia coli by the ionic detergent sodium-lauryl sarcosinate. J Bacteriol 115, 717-722. Fischer, K., Weber, A., Brink, S., Arbinger, B., Schunemann, D., Borchert, S., Heldt, H. W., Popp, B., Benz, R. \& Link, T. A. (1994). Porins from plants. Molecular cloning and functional characterization of two new members of the porin family. J Biol Chem $\mathbf{2 6 9}$, 25754-25760.

Guerry, P., Alm, R. A., Power, M. E., Logan, S. M. \& Trust, T. J. (1991). Role of two flagellin genes in Campylobacter motility. J Bacteriol 173, 4757-4764.

Hansel, A., Schmid, A., Tadros, M. H. \& Jurgens, U. J. (1994). Isolation and characterization of porin from the outer membrane of Synechococcus PCC 6301. Arch Microbiol 161, 163-167.

von Heijne, G. (1994). Signals for protein targeting into and across membranes. Subcell Biochem 22, 1-19.

Kuwabara, T., Reddy, K. J. \& Sherman, L. A. (1987). Nucleotide sequence of the gene from the cyanobacterium Anacystis nidulans R2 encoding the $\mathrm{Mn}$-stabilizing protein involved in photosystem II water oxidation. Proc Natl Acad Sci USA 84, 8230-8234.

Laudenbach, D. E., Herbert, S. K., MCDowell, C., Fork, D. C., Grossman, A. R. \& Straus, N. A. (1990). Cytochrome $c-553$ is not required for photosynthetic activity in the cyanobacterium Synechococcus. Plant Cell 2, 913-924.

Laudenbach, D. E., Ehrhardt, D., Green, L. \& Grossman, A. (1991). Isolation and characterization of a sulfur-regulated gene encoding a periplasmically localized protein with sequence similarity to thodanese. J Bacteriol 173, 2751-2760.

Mackle, M. M. \& Zilinskas, B. A. (1994). Role of signal peptides in targeting of proteins in cyanobacteria. J Bacteriol 176, 1857-1864.

Masui, Y., Mizuno, T. \& Inouye, M. (1984). Novel high-level expression cloning vehicles: $10^{4}$-fold amplification of Escherichia coli minor protein. Bio/Technology 3, 81-85.

Matsuyama, S., Inokuchi, K. \& Mizushima, S. (1984). Promoter exchange between $o m p F$ and $o m p C$, genes for osmoregulated major outer membrane proteins of Eschericbia coli K-12. J Bacteriol 158, 1041-1047.

Mizuno, T. \& Mizushima, S. (1987). Isolation and characterization of deletion mutants of $o m p R$ and $e n v Z$, regulatory genes for expression of the outer membrane proteins OmpC and OmpF in Escherichia coli. J Biochem 101, 387-396.

Mizuno, T. \& Mizuzhima, S. (1990). Signal transduction and gene regulation through the phosphorylation of two regulatory components: the molecular basis for the osmotic regulation of the porin gene. Mol Microbiol 4, 1077-1082.

Mizuno, T., Chou, M.-Y. \& Inouye, M. (1983). A comparative study on the genes for three porins of the Escherichia coli outer membrane: DNA sequence of the osmoregulated $o m p C$ gene. $J$ Biol Chem 258, 6932-6940.

Murata, N. \& Omata, T. (1988). Isolation of cyanobacterial plasma membranes. Methods Enzymol 167, 245-251.

Nakai, M., Tanaka, A., Omata, T. \& Endo, T. (1992). Cloning and characterization of the $\sec Y$ gene from the cyanobacterium Synechococcus PCC7942. Biocbim Biophys Acta 1171, 113-116.

Nakai, M., Nohara, T., Sugita, D. \& Endo, T. (1994). Identification and characterization of the SecA protein homologue in the cyanobacterium Synechococcus PCC7942. Biocbem Biophys Res Commun 200, 844-851.

Nikaido, H. (1979). Nonspecific transport through the outer membrane. In Bacterial Outer Membrane: Biogenesis and Function, pp. 319-361. Edited by M. Inouye. New York: John Wiley and Sons. 
Packer, J. C., Andre, D. \& Howe, C. J. (1995). Cloning and sequence analysis of a signal peptidase I from the thermophilic cyanobacterium Phormidium laminosum. Plant Mol Biol 27, 199-204.

Philbrick, J. B. \& Zilinskas, B. A. (1988). Cloning, nucleotide sequence and mutational analysis of the gene encoding the Photosystem II manganese-stabilizing polypeptide of Synechocystis 6803. Mol Gen Genet 212, 418-425.

Pugsley, A. P. (1993). The complete general secretory pathway in Gram-negative bacteria. Microbiol Rev 57, 50-108.

Rippka, R., Deruelles, J., Waterbury, J. B., Herdman, M. \& Stanier, R. Y. (1979). Generic assignments, strain histories and properties of pure cultures of cyanobacteria. J Gen Microbiol 111, 1-61.

Shestakov, S. V., Anbudurai, P. R., Stanbekova, G. E., Gadzhiev, A., Lind, L. K. \& Pakrasi, H. B. (1994). Molecular cloning and characterization of the $\operatorname{ctp} A$ gene encoding a carboxyl-terminal processing protease. Analysis of a spontaneous photosystem IIdeficient mutant strain of the cyanobacterium Synechocystis sp. PCC6803. J Biol Chem 269, 19354-19359.

Snyder, M. \& Davis, R. W. (1985). Screening igt11 expression libraries with antibody probes. In Hybridoma Technology in Biosciences and Medicine, pp. 397-406. Edited by T. Springer. New York: Plenum Press.
Suzuki, T., Itoh, A., Ichihara, S. \& Mizushima, S. (1987). Characterization of the $\operatorname{sp} A$ gene coding for protease IV, a signal peptide peptidase of Escherichia coli. J Bacteriol 169, 2523-2528.

Varley, J. P., Moehrle, J. J., Manasse, R. S., Bendall, D. S. \& Howe, C. J. (1995). Characterization of plastocyanin from the cyanobacterium Phormidium laminosum: copper-inducible expression and SecA-dependent targeting in Eschericbia coli. Plant Mol Biol 27, 179-190.

Vieira, J. \& Messing, J. (1987). Production of single stranded plasmid DNA. Methods Enzymol 153, 3-11.

Zhang, C.-C., Durand, M.-C., Jeanjean, R. \& Joset, F. (1989). Molecular and genetical analysis of the fructose-glucose transport system in the cyanobacterium Synechocystis PCC6803. Mol Microbiol 3, 1221-1229.

Zhang, L., Pakrasi, H. B. \& Whitmarsh, J. (1994). Photoautotrophic growth of the cyanobacterium Synechocystis sp. PCC6803 in the absence of cytochrome 6553 and plastocyanin. J Biol Cbem 269, $5036-5042$.

Received 17 November 1995; revised 29 February 1996; accepted 18 March 1996. 